\title{
The $f$-ratio Quantification Method for X-ray Microanalysis with a Field Emission SEM Applied to Multi-Elements Specimen
}

\author{
Chaoyi Teng ${ }^{1}$, Hendrix Demers ${ }^{1}$, Nicolas Brodusch ${ }^{1}$ and Raynald Gauvin ${ }^{1}$ \\ 1. Department of Mining and Materials Engineering, McGill University, Montreal, Quebec, Canada.
}

A scanning electron microscope (SEM) / energy dispersive spectroscopy (EDS) system has become one general-purpose instrument for quantitative X-ray microanalysis because it is fast and easily operated. But compared with the standard quantitative analysis performed with an electron probe microanalyzer (EPMA) / wavelength-dispersive X-ray spectroscope (WDS) system, the accuracy of the standardless EDS analysis should be improved. In this work, the $f$-ratio X-ray quantification method was performed with a field emission SEM (FE-SEM)/EDS system on a $\mathrm{Mg}_{45}-\mathrm{Al}_{28}-\mathrm{Zn}_{27}$ alloy to acquire the standard quantitative maps [1]. The FE-SEM allows for the quantitative X-ray microanalysis at a low electron beam energy with a probe diameter at the nm level. However, the cold field electron gun cannot provide a constant probe current. Thus, it is not appropriate to perform the standard k-ratio quantification which requires the current conditions should be the same for the specimen and standard. The $f$-ratio method does not have this requirement, and can be easily applied to a FE-SEM to perform high spatial resolution quantitative X-ray microanalysis [2].

The $f$-ratio method, developed by Horny et al. was applied to a $\mathrm{Mg}_{45}-\mathrm{Al}_{28}-\mathrm{Zn}_{27}$ alloy [1]. Figure 1 shows its BSE image and three different phases can be distinguished. Even though this sample is not homogeneous, when the complete image is analyzed, the composition seems to be stable. Its composition was determined by inductively coupled plasma atomic emission spectroscopy (ICP-AES) as $27.76 \mathrm{wt}$. \% $\mathrm{Al}, 44.74$ wt. $\% \mathrm{Mg}$, and 27.59 wt. $\% \mathrm{Zn}$ [3]. The $f$-ratio method was used to acquire the quantitative Xray map of the $\mathrm{Mg}_{45}-\mathrm{Al}_{28}-\mathrm{Zn}_{27}$ alloy, using a ratio of net X-ray intensity defined as [1]:

$$
f_{M g}=\frac{I_{M g}}{I_{M g}+I_{A l}+I_{Z n}}
$$

In the above equation, $I_{M g}, I_{A l}$, and $I_{Z n}$ are the net intensities of the $\mathrm{K}$ lines of $\mathrm{Mg}, \mathrm{Al}$, and $\mathrm{Zn}$. Because they are taken from one spectrum, the probe current can be canceled out in this ratio, so there is no need to measure the probe current. The calibration curves which relate the $f$-ratio and the weight fraction were computed by Monte Carlo simulations using the MC X-ray software [4]. Calibration factors were calculated with the standard samples of known composition to eliminate the uncertainties in the parameters of X-ray generation and detection. The element concentrations were determined by multidimension interpolation of the calibration curves.

Figure 2 displays the $f$-ratio quantitative $\mathrm{X}$-ray maps of the $\mathrm{Mg}_{45}-\mathrm{Al}_{28}-\mathrm{Zn}_{27}$ alloy at an accelerating voltage of $20 \mathrm{kV}$. The compositional changes of the three elements in the three phases are presented. Table 1 lists the concentrations of the three elements in the complete area shown in Figure 2 measured with the EDS standardless quantitative analysis and the $f$-ratio method calibrated with standards. 


\section{References:}

[1] P. Horny, Ph.D thesis, in department of Mining, Metals and Materials Engineering, McGill University (2006).

[2] P. Horny et al, Microscopy and Microanalysis 16 (2010), p. 821.

[3] J.F. Le Berre et al, Final Report Submitted to Carl D. Fuerst (2007).

[4] R. Gauvin and P, Michaud, Microscopy and Microanalysis 15, 2, (2009), p. 488.

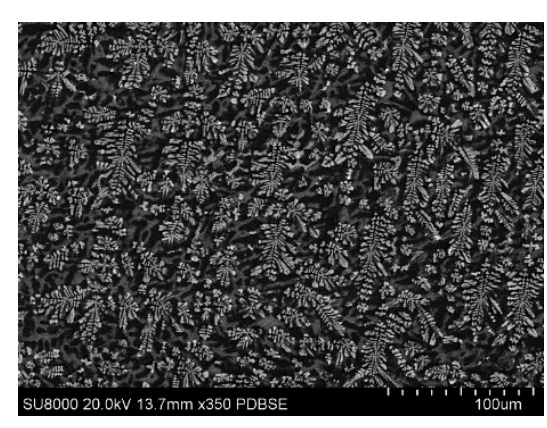

Figure 1. BSE image of $\mathrm{Mg}_{45}-\mathrm{Al}_{28}-\mathrm{Zn}_{27}$ alloy at an accelerating voltage of $20 \mathrm{kV}$.
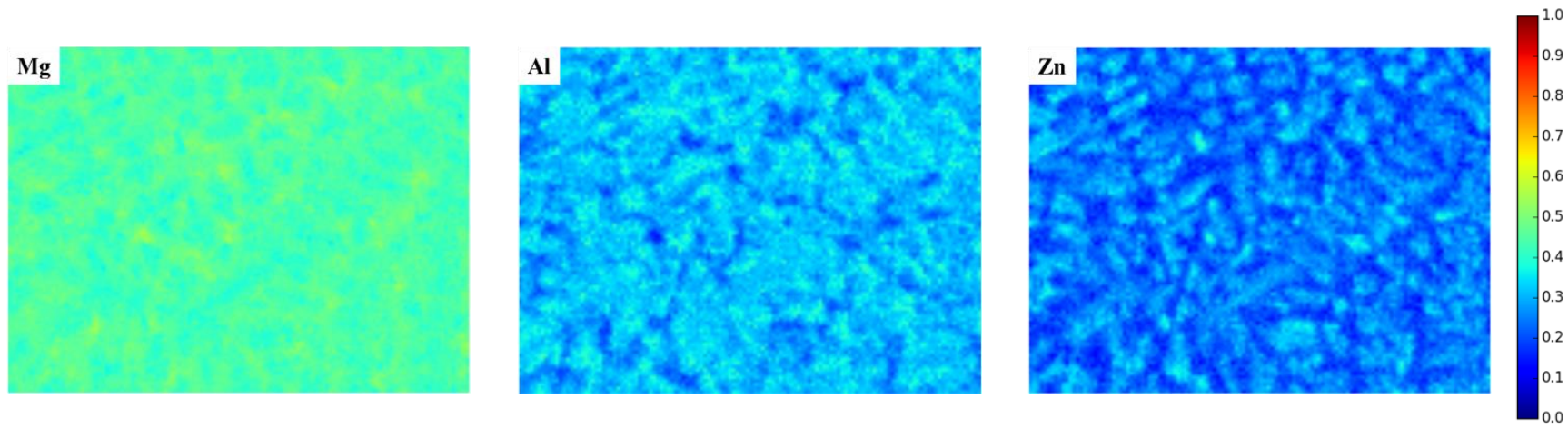

Figure 2. The $f$-ratio quantitative $\mathrm{X}$-ray maps of the $\mathrm{Mg}_{45}-\mathrm{Al}_{28}-\mathrm{Zn}_{27}$ alloy at an accelerating voltage of 20 $\mathrm{kV}$.

\begin{tabular}{|c|c|c|c|}
\hline \multirow{2}{*}{$\begin{array}{c}\text { Quantification } \\
\text { Method }\end{array}$} & $\mathrm{Mg}$ & $\mathrm{Al}$ & $\mathrm{Zn}$ \\
\cline { 2 - 4 } & $44.74 \%$ & $27.76 \%$ & $27.50 \%$ \\
\hline ICP-AES & $46.76 \%$ & $26.42 \%$ & $26.82 \%$ \\
\hline EDS Standardless & $44.40 \%$ & $27.18 \%$ & $28.42 \%$ \\
\hline$f$-ratio Method & & & \\
\hline
\end{tabular}

Table 1. Weight fractions of $\mathrm{Mg}, \mathrm{Al}$ and $\mathrm{Zn}$ in the complete area shown in Figure 2 measured with ICPAES, EDS standardless quantitative analysis, and the f-ratio method calibrated with standards. 